\title{
CUAUHTÉMOC, “EL HÉROE COMPLETO”1 LA CONMEMORACIÓN DEL ÚLTIMO EMPERADOR AZTECA EN LA CIUDAD DE MÉXICO DURANTE EL PORFIRIATO
}

$(1887-1911)$

\section{Lara Campos Pérez}

Escuela Nacional de Biblioteconomía y Archivonomía

$\mathrm{Z}_{\mathrm{n}}$ el último tercio del siglo xix, en el escenario de lo que Eric Hobsbawm llamó - usando una metáfora muy ad oc para la época - "la producción de tradiciones en serie”, fue en el que arrancó en México la conmemoración del último emperador azteca. ${ }^{2}$ Durante las décadas finales del novecientos, a su propio ritmo y con sus propias idiosincrasias, las naciones del mundo occidental - representadas simbólicamente en muchos casos mediante exuberantes matronas vestidas con túnicas clásicas - caminaron de forma inexorable, no sólo hacia el progreso al que todas querían llegar, sino también, en dirección cronológicamente inversa, hacia un pasado que les proporcionara información suficiente sobre sus propias esencias, que con la velocidad

Fecha de recepción: 27 de noviembre de 2015

Fecha de aceptación: 26 de febrero de 2016

${ }^{1}$ Manuel Altamirano, "Cuauhtémoc", Diario del Hogar (20 ago. 1899).

${ }^{2}$ Hoвsbawm, “La fabricación”, pp. 273-318. 
de la vida moderna se habrían ido quedando perdidas en el camino. En ese echar la vista atrás, como ha demostrado la abundante historiografía sobre el tema publicada en las últimas dos o tres décadas, se desempolvaron del baúl de la historia personajes y acontecimientos a los que, sin pudor y probablemente sin remordimiento, se les atribuyeron cualidades excepcionales para entender la nación presente. Desde el pasado más remoto al más inmediato, cualquier episodio era susceptible de ser rescatado del olvido o del conocimiento erudito si con él se podía hacer pedagogía nacional. Porque para eso era precisamente para lo que debía servir en última instancia esa recuperación sistemática y selectiva del pasado: para hacer nacionales a los connacionales, proveyéndoles de un marco referencial - tanto geográfico como cronológico - mayor al de sus regiones de origen, que favoreciera el surgimiento y consolidación de un imaginario colectivo en clave nacional.

Y para que esta pedagogía nacional fuera realmente efectiva no debía quedarse únicamente entre las élites o limitarse a espacios reducidos, como había ocurrido en las primeras décadas del novecientos, sino que debía salir en busca del ciudadano al espacio público en el que se desarrollaba su vida. Los incipientes altares de la patria con los que desde finales del siglo xix comenzó a quedar salpicada la geografía de los países occidentales desempeñaron un papel de primer orden a este respecto, pues al mismo tiempo que se convirtieron en memoria imperecedera del personaje o acto representado, fueron también con frecuencia el escenario en el que se llevaron a cabo sus particulares rituales conmemorativos, que, en tanto actos colectivos repetidos y simbólicos, estaban llamados a convertirse en 
eficaces mecanismos al servicio de las nuevas religiones cívicas nacionales. ${ }^{3}$

La conmemoración en honor a Cuauhtémoc surgió, pues, en esta coyuntura histórica de definición de esencias patrias y relatos de legitimación histórica, cuyo debate en México estuvo marcado durante aquellos años por varios factores, entre ellos y de forma significativa por la postura hispanófila o hispanófoba de aquellos que se encargaron de su reconstrucción. ${ }^{4}$ La recuperación de la memoria de Cuauhtémoc, uno de los pocos personajes del pasado lejano mexicano que pasó a engrosar la lista del panteón decimonónico de héroes nacionales y que por ello se hizo acreedor de una conmemoración propia, había comenzado a producirse desde mediados del siglo xIX, motivada en parte por una vindicación del pasado indígena que buscaba reducir el peso que la herencia hispana tenía en la moderna nación mexicana. A él le habían dedicado libros y discursos en las décadas centrales de la centuria personajes de la talla de Benito Juárez, Ignacio Manuel Altamirano o Manuel Payno, cuyos relatos contribuyeron a la conformación mítica de este personaje histórico, al mismo tiempo que a través de él se iban definiendo las esencias patrias de lo que era o debía ser la mexicanidad. ${ }^{5}$ Porfirio Díaz, por tanto, lo único que hizo, desde el punto

${ }^{3}$ El término "altar de la patria” y su significado simbólico político en Mosse, La nacionalización; sobre conmemoraciones nacionales en el siglo XIX véase GILLIs, Commemorations; el concepto de "religión cívica" en Gentile, "Fascism".

${ }^{4}$ Pérez Vejo, "La difícil herencia".

5 Sobre la recuperación histórica y literaria de Cuauhtémoc en el siglo xix, García Quintana, Cuaubtémoc en el siglo XIX; Ferreyra, "Cuauhtémoc, hombre". 
de vista de la recuperación del personaje histórico, fue darle continuidad a una tendencia en ascenso. Sin embargo, desde el punto de vista de las prácticas culturales de la política, al aprobar la propuesta del establecimiento de una conmemoración anual, tomó una decisión de mucha mayor trascendencia: creó un altar de la patria - además en un lugar emblemático de la ciudad, como lo era el Paseo de la Reforma $-{ }^{6}$ en torno del cual se rendiría culto civil a uno de los héroes de la nación.

Una vez convertida en conmemoración anual, la repetición cíclica de la celebración del 21 de agosto permitió crear un espacio físico e intelectual adecuado para la reflexión sobre el pasado y el futuro de la nación, a partir de aquellos valores con los que se relacionó al personaje. Entre ellos, aquellos derivados de su pertenencia a la civilización azteca, así como los relativos a lo que se interpretó como la primera lucha por la independencia nacional, o los propios de su condición de indígena; un conjunto de temas que, además, a lo largo de los casi 25 años en los que se llevó a cabo esta celebración, experimentaron variaciones en su interpretación y oscilaciones en cuanto a su relevancia. El estudio histórico de esta efeméride resulta, por tanto, interesante desde varios puntos de vista, porque, al mismo tiempo que nos permite conocer el uso y funcionamiento de uno de los primeros altares de la patria instalados en la Ciudad de México, nos brinda la oportunidad de acercarnos a los debates que tuvieron lugar durante aquellos años en torno de ciertos aspectos de la vida política y cultural del país, que se activaban en relación con este personaje y su efeméride.

6 Tenembaum, "Streetwise History". 


\section{LA ELECCIÓN DE LA FECHA Y EL ESTABLECIMIENTO}

DE LA RITUALIDAD

La primera conmemoración del último emperador azteca se produjo después de la inauguración del monumento erigido en su honor en el Paseo de la Reforma y surgió a partir de una iniciativa ciudadana. El monumento a Cuauhtémoc, cuya fecha de inauguración había sido establecida diez años antes por quien fuera el principal promotor de su ejecución, Vicente Riva Palacio, debía tener lugar el 21 de agosto de 1887. ${ }^{7}$ Menos de un mes antes de que dicha inauguración se efectuase, un grupo de ciudadanos encabezado por Demetrio Mejía dirigía una carta al Ayuntamiento de la capital solicitando "señalar un día del año a la memoria" del emperador - algo que en su opinión "no sólo [era] de justicia, sino de deber" - y proponían que éste fuera el 13 de agosto, pues esa había sido la fecha en que, no pudiendo mantener por más tiempo el asedio, Cuauhtémoc había entregado la ciudad y con ella el imperio a Cortés. Entre las múltiples razones que se exponían para la dedicación de un día del calendario cívico nacional a este héroe se encontraba la consideración de que él había sido el "primer Mártir de la Independencia”, así como el hecho de que su juventud, su civismo y su valor lo convertían en uno de los mejores ejemplos para la ciudadanía. ${ }^{8}$ En la elección de la fecha hecha por este comité ciudadano quizá pudo haber influido el que, justo 20 años antes, un Benito Juárez pletórico tras la restauración de la República y necesitado de un afianzamiento

\footnotetext{
7 García Quintana, Cuaubtémoc en el siglo XIX, p. 25.

8 AHCM, Festividades, vol. 1059, exp. 42.
} 
simbólico político, decidiera llevar a cabo un 13 de agosto la inauguración del primer monumento en memoria de Cuauhtémoc erigido en la ciudad. ${ }^{9}$

La carta fue remitida desde el Ayuntamiento al gobierno del Distrito Federal y, pocos días más tarde, Ceballos, en su calidad de gobernador de la entidad, daba respuesta a la misma señalando el agrado que le producía la iniciativa ciudadana (que no dudaba en respaldar), pero haciendo explícita su discrepancia respecto a la fecha, pues el 13 de agosto había sido el "día en que con la toma de la capital terminó la guerra de Conquista” y esto, es su opinión, "no rec[ordaba] a los mexicanos un acontecimiento conveniente". En su lugar, proponía que ésta se celebrara el 21 de agosto, ya que, a partir de una serie de pesquisas que había mandado hacer, ésa parecía ser la fecha en que Cuauhtémoc "soportó los horrores del tormento con un valor y una serenidad sin ejemplo en la historia", hecho que dignificaba al héroe y le abría "el templo de la inmortalidad $[\ldots]$ con la incomparable grandeza de su infortunio". ${ }^{10}$ La propuesta fue aceptada tanto por el Ayuntamiento como por el grupo de ciudadanos encabezado por Demetrio Mejía; y con la premura que demandaba la inminencia de la fecha comenzaron los preparativos de la conmemoración.

Sin embargo, la pertinencia de la elección de la fecha para la conmemoración anual en honor a Cuauhtémoc siguió siendo objeto de reflexión durante algunos años más, algo relativamente anómalo en la fijación del calendario cívico, pues a cada héroe o a cada santo laico se le asigna un día específico (el de su nacimiento, su muerte, su acción principal)

9 Fulton, "Cuauhtémoc awakened", p. 13.

10 AHCM, Festividades, vol. 1059, exp. 42. 
en torno del que se concentra todo el valor simbólico del mismo. ${ }^{11}$ En el caso del último rey azteca, sin embargo, no pareció existir inicialmente un consenso tan rotundo al respecto. Así pues, ya el mismo día en que se llevaba a cabo la inauguración de la estatua en el Paseo de la Reforma, uno de los destacados oradores que participó en ella, Francisco Sosa, proponía en su discurso que dicha conmemoración debía celebrarse el 16 de septiembre, dentro de las fiestas patrias, pues si el rey azteca había sido el primer mártir de la patria, lo lógico, en su opinión, era que se le festejara junto a los demás. ${ }^{12} \mathrm{La}$ iniciativa del afamado escritor de origen campechano no tuvo demasiado eco y pronto cayó en el olvido. La que sí se barajó seriamente como alternativa fue la que propuso unos meses más tarde Miguel S. Macedo. En una carta enviada al Ayuntamiento, fechada en diciembre de 1887, el catedrático argumentaba que la celebración debía exaltar no a un único personaje sino a toda una cultura y, por eso, fijarla el 21 de agosto resultaba injusto respecto al resto de guerreros aztecas que habían luchado contra el conquistador extremeño. Por tanto, él abogaba por que la celebración fuera trasladada al 30 de junio, ya que en ese día, en 1520 y 1521 respectivamente, habían ocurrido hechos de armas favorables a los ejércitos indígenas - entre ellos, la famosa victoria de la Noche Triste- cuyo recuerdo era más honroso que el del martirologio al que había sido sometido

${ }^{11}$ La bibliografía sobre las conmemoraciones cívicas es extensa; remitimos a la "Introducción" de la obra ya citada de Gillis, Commemorations.

12 Fragmento del discurso reproducido en García Quintana, Cuaubtémoc en el siglo XIX, p. 25; la prensa de aquellos días también tomó parte en el debate en torno a la pertinencia en la elección de la fecha. Ferreyra, "Cuauhtémoc, hombre", p. 72. 
Cuauhtémoc. ${ }^{13} \mathrm{El}$ mismo argumento fue expuesto durante los dos años siguientes por Francisco León de la Barra, entonces regidor de festividades del gobierno del Distrito, que insistía en que el 30 de junio había sido un día "doblemente célebre en la vida del héroe” y que, por tanto, resultaba más idóneo para la celebración, además de que no existía certeza científica de que el martirio se hubiera producido efectivamente el día 21 de agosto, como en general se creía. ${ }^{14}$

Estas disquisiciones en torno a la fecha de la conmemoración acabaron disolviéndose con el paso de los años y de manera consuetudinaria la que se fijó como tal fue el 21 de agosto; casualmente, un día después de la fecha establecida para la conmemoración de la batalla de Churubusco de 1847. La proximidad de ambas fechas, que, como señalaba en 1903 un editorialista del Diario del Hogar, hacían referencia a dos derrotas de las armas mexicanas - aunque dos derrotas investidas de gloria, en su opinión,$-{ }^{15}$ no implicaba inicialmente ningún conflicto, pues ambos episodios se interpretaron como momentos distintos de una misma lucha: la que históricamente la nación mexicana había librado contra el invasor extranjero, como mostraba la ilustración a doble página publicada en El Hijo del Abuizote en 1901 (figura 1), donde tanto el general Anaya como Cuauhtémoc eran representados en el momento de hacer frente a sus enemigos tras la derrota, sin que ello restara un ápice de dignidad a ambos personajes. Sin embargo, la proximidad de ambas celebraciones tenía un inconveniente de orden

13 AHCM, Festividades, vol. 1059, exp. 42.

14 AHCM, Festividades, vol. 1059, exp. 43.

15 Diario del Hogar (21 ago. 1903). 
práctico: la presencia de don Porfirio solía limitarse a una de ellas, ya que acudir a los dos - sobre todo a medida que iban pasando los años - debía resultar agotador para el general, que, por otra parte, debía ahorrar energías para las cercanas fiestas septembrinas. La participación del aparato oficial, no obstante, hacía inevitablemente bascular la relevancia otorgada a cada una de las fechas, como lo hicieron notar algunos de los comentaristas políticos de aquellos años, que además se quejaban de que Díaz tuviera tiempo de desahogar su apretada agenda social, pero se mostrara indiferente ante "los hechos gloriosos que debíamos tener presentes". ${ }^{16}$

\section{Figura 1}

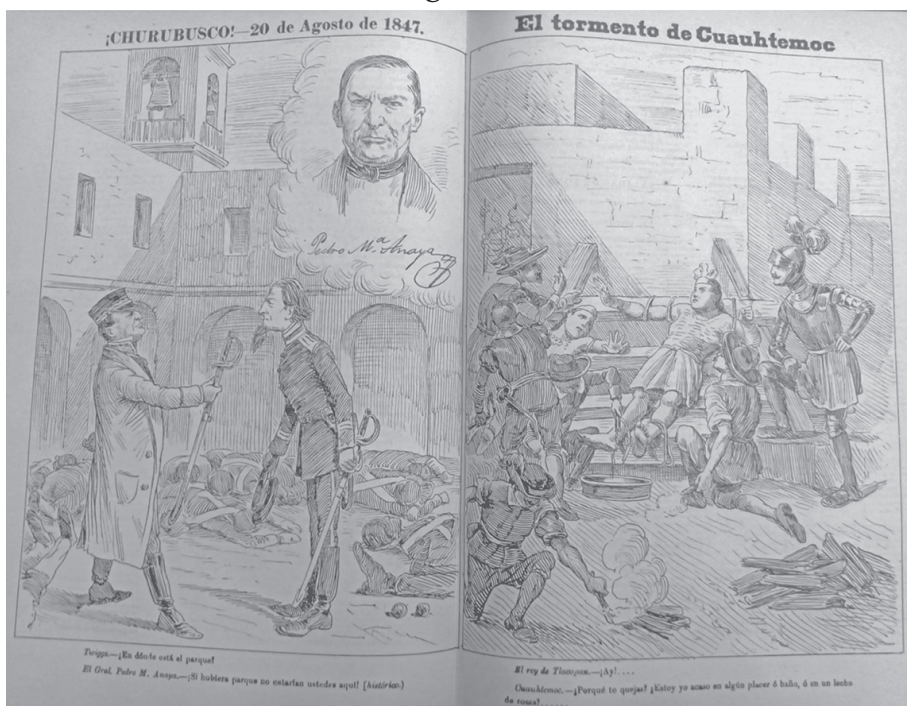

El Hijo del Abuizote (25 ago. 1901)

${ }_{16}$ Diario del Hogar (21 ago. 1895), el comentario era en relación con la ausencia del aparato oficial en las celebraciones de Churubusco. 
En cuanto a la ritualidad, ésta quedó -igual que la fecha - pautada a partir de la que se estableció el día de la inauguración del monumento en el Paseo de la Reforma, a la que se le hicieron algunas variaciones de tipo formal con el paso de los años. Sin embargo, el despliegue de medios realizado en aquella primera ocasión fue menguando paulatinamente, haciendo menos vistosa la ceremonia, aunque nunca llegó a desaparecer. El Ayuntamiento de la Ciudad de México fue el principal encargado de su organización, cuyas gestiones consistían básicamente en conseguir uno o varios oradores de prestigio para el discurso principal - asunto que no siempre resultó tan fácil como cabría esperar-, así como en cursar invitaciones a los ayuntamientos del resto de municipios del Distrito, además de asegurar la presencia de bandas de música y tener listos los arreglos florales. ${ }^{17}$ En estos trabajos también tomaron eventualmente parte agrupaciones mutualistas de obreros, que, según apunta Carlos Illades, aprovechaban su participación en estos actos cívicos para mostrar su apego hacia los héroes históricos de la nación, así como un medio para visibilizarse simbólicamente en la sociedad. ${ }^{18} \mathrm{El}$ presupuesto aprobado para la ejecución de los festejos osciló entre los 1000 pesos asignados en 1889, cuando la conmemoración se encontraba en su momento álgido, a los 200 , que fue el monto habitual a partir de 1897; unas cantidades bastante modestas si

17 En 1891, Julio Zárate, Francisco Bulnes y Eduardo del Valle, alegando motivos diversos, declinaron la invitación hecha por el Ayuntamiento para pronunciar el discurso principal en honor a Cuauhtémoc, que al final quedó a cargo de Manuel G. Revilla. AHCM, Festividades, vol. 1059, exp. 42.

${ }^{18}$ Illades, Las otras ideas, pp. 212-215. 
se comparan con las empleadas en otros festejos, como el 16 de septiembre o el 5 de mayo, cuyo monto nunca fue menor a los 2000 pesos y llegó a ascender hasta los $9000 .{ }^{19}$ La única conmemoración anual que remitía a los orígenes remotos de la nación mexicana resultaba, por tanto, poco onerosa para las arcas públicas.

Pero si la celebración del último emperador azteca fue palideciendo con el paso del tiempo, su primera puesta en escena, que tuvo lugar en los años en que se sentaron las bases del culto a la personalidad construido en torno a Porfirio Díaz, ${ }^{20}$ resultó apoteósica. Aquel 21 de agosto, desde temprana hora de la mañana, comenzaron a llegar a las inmediaciones del monumento a Cuauhtémoc en el Paseo de la Reforma los diversos grupos que iban a formar parte de ella. Desde la tarde antes, tanto la tribuna oficial como la de invitados, así como el basamento del propio monumento al emperador azteca habían quedado cubiertos con una esmerada ornamentación floral, que combinaba a partes iguales el estilo “de los antiguos escultores mexicas” con la simbología nacional decimonónica, todo ello aderezado con toques paisajistas a lo José María Velasco. Así, por ejemplo, mientras que sobre los dos arcos que flanqueaban el monumento se erigían "el águila nacional y las banderas de la patria, todo hecho con flores", el dosel de la tribuna oficial estaba decorado con una cenefa de estilo azteca y en la parte del fondo de la misma se podía apreciar "un vasto lienzo azul, representando el espléndido valle de México,

19 AHCM, Festividades, para el presupuesto de la conmemoración a Cuauhtémoc: vol. 1059, exp. 42; para el presupuesto de las otras conmemoraciones: vol. 1608, exps. 16, 18 y 29.

${ }^{20}$ Cosío Villegas, El Porfiriato. Vida política interior, pp. 166-167. 
con sus pensiles de eterno verdor, su cielo fulgurante y sus altivos volcanes". ${ }^{21}$

En este cuidado escenario, tras la llegada del presidente de la República y de la comitiva oficial - que incluía representantes diplomáticos de algunos países como España, Francia y Guatemala -, a las 9 en punto de la mañana, dio inicio la solemne ceremonia. Ésta comenzó con la declamación de un primer discurso a cargo del historiador y arqueólogo Alfredo Chavero; a continuación se produjo la develación de la estatua - llevada a cabo por Díaz - y la colocación de coronas de flores en el pedestal; posteriormente tuvo lugar la interpretación del Himno Nacional por parte de las bandas militares, a lo que siguió la recitación de una nueva tanda de poesías - en la que participó, entre otros, la escritora española Concepción Gimeno de Flaquer, a fin de demostrar que la rivalidad histórica entre ambas naciones ya no se encontraba vigente-, así como la declamación de nuevos discursos, algunos de ellos en náhuatl; para cerrar, se llevó a cabo una presentación de danzas y músicas de los pueblos indígenas de las distintas delegaciones del Distrito. A las 12 de la mañana se dio por concluida la ceremonia oficial, aunque la música y las danzas se prolongaron durante algunas horas más. Según la prensa del día siguiente, la asistencia al acto fue multitudinaria y socialmente diversa, pues en torno al monumento a Cuauhtémoc se vio desde "el más engominado aristócrata, hasta el indígena más humilde”. ${ }^{22}$

21 La crónica de la jornada más completa en El Siglo XIX (22 ago. 1887), todas las citas proceden de ahí; una descripción minuciosa de este acto en FERREYRA, "Cuauhtémoc, hombre”, pp. 72-83; sobre el estilo azteca en las construcciones y decoraciones véase RAMírEz, "Vertientes nacionalistas”. 22 El Siglo XIX (22 ago. 1887). 
Durante los siguientes cinco años - salvo en lo relativo a la develación de la estatua - la ceremonia conmemorativa se llevó a cabo en términos parecidos a los de esta primera puesta en escena: se erigieron tribunas con decoración inspirada en motivos aztecas para los invitados de honor, se depositaron coronas de flores en el basamento del monumento, se pronunciaron discursos en honor a Cuauhtémoc, tanto en castellano como en náhuatl, y los pueblos indígenas de las distintas delegaciones del Distrito ejecutaron piezas de música y danzas, todo ello sancionado con la presencia del general Díaz y de su comitiva ministerial. Sin embargo, a partir de 1893, la preocupación oficial por la efeméride fue decayendo y, con ello, parte de la parafernalia simbólica desplegada, pues dejaron de levantarse las tribunas (los discursos se pronunciaron a partir de entonces desde el quiosco que había en las inmediaciones) y se redujeron los ornamentos florales. Este desinterés gubernamental hacia la única efeméride que remitía al pasado lejano mexicano no pasó desapercibido para los críticos del régimen, para quienes, además, los festejos cívicos constituían la mejor forma de pedagogía liberal. ${ }^{23}$ Así, por ejemplo, en 1894, un editorialista de El Monitor Republicano, tras consignar lo poco vistosa que había sido la celebración de ese 21 de agosto, se compadecía de Cuauhtémoc, que después de haberse sacrificado por "el bien de las presentes y futuras generaciones [...]. Después de asado como cabeza de horno, ¡ni quién le haga caso!”. ${ }^{24}$

$\mathrm{Al}$ arrancar el siglo xx, la ceremonia siguió manteniendo la misma estructura sencilla de los años anteriores, pero con

${ }^{23}$ Bastian, Los disidentes, pp. 202-204.

${ }^{24}$ El Monitor Republicano (26 ago. 1894). 
la introducción de algunas pequeñas variaciones. Entre ellas, quizá las más relevantes fueron, por una parte, que el presbítero José Pilar Sandoval, miembro de la Sociedad de Geografía y Estadística, se convirtiera en el principal orador de la ceremonia - lo que amplió las simpatías de los católicos hacia la efeméride-, y, por otra, la supresión de los representantes de los pueblos indígenas de las delegaciones del Distrito, cuyo papel en el festejo recayó a partir de entonces en grupos de niños. Durante los primeros años de la centuria, estos niños, procedentes la mayoría de las veces del asilo de niños huérfanos dirigido por el sacerdote Hunt Cortés, fueron adecuadamente caracterizados con "trajes aztecas muy luminosos y apropiados" 25 - como mostraba el reportaje fotográfico realizado con motivo de la efeméride por El Mundo Ilustrado de 1900 (véase la figura 2) - y se encargaron de entonar canciones en náhuatl, así como el Himno Nacional en el cierre de la ceremonia.

Para 1910, la conmemoración en honor a Cuauhtémoc - como le ocurrió a casi todas las celebraciones cívicas porfirianas en ese año del Centenario - estuvo revestida de un mayor boato, pues incluyó oradores destacados, como el entonces joven académico Alfonso Teja Zabre, que se encargó del discurso en castellano, mientras que el pronunciado en náhuatl quedó a cargo del lingüista Luis Álvarez. Además, se incluyó la presencia de un grupo de niñas, que ya no iban caracterizadas con indumentaria de estilo azteca, sino vestidas de blanco y con sombreros de paja "que tenían lazos con los nombres de las heroínas de México, Josefa Ortiz de Domínguez, Leona Vicario, Rodríguez de Lazarín [y] Rita

${ }^{25}$ El Imparcial (22 ago. 1900). 
Figura 2

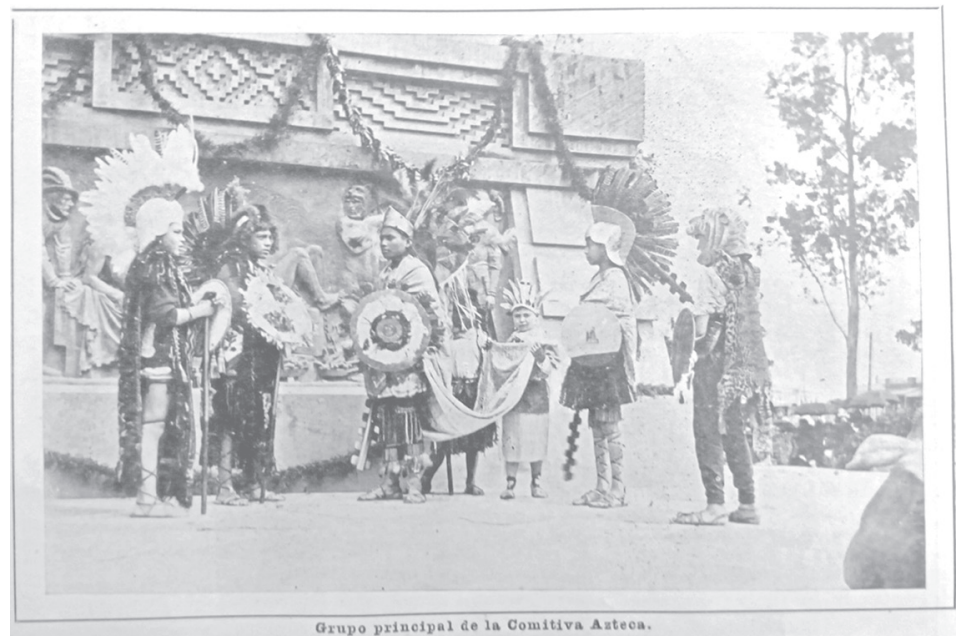

El Mundo Ilustrado (22 ago. 1900)

Pérez de Toledo". La ceremonia concluyó con la interpretación de algunas piezas de música por parte de las bandas militares, entre las que se incluyó La Boheme de Puccini. A pesar de este intento de reactivación del festejo, desde el punto de vista oficial la celebración de ese año quedó opacada, pues al final de la misma llegó un grupo "como de mil personas provistas de banderolas y estandartes de las agrupaciones antirreeleccionistas de la capital" encabezadas por la asociación femenina Club Hijas de Cuauhtémoc, que, después de depositar coronas de flores a los pies del monumento, comenzaron a gritar vivas a Madero y a hacer peroraciones "frente a la estatua del mártir indio". ${ }^{26}$

${ }^{26}$ El Imparcial omitió cualquier referencia a la efeméride en su edición del día siguiente; todas las citas proceden de El País (22 ago. 1910). 
A pesar de esta última reactivación de la conmemoración de Cuauhtémoc, las celebraciones públicas en su honor, incluso en sus años de mayor esplendor, resultaron, como acabamos de ver, actos sencillos, que, a diferencia de otros rituales cívicos ejecutados durante el porfiriato - sobre todo a partir del inicio del siglo $\mathrm{xx}-{ }^{27}$ nunca estuvieron enfocados a la promoción de la movilización multitudinaria de la ciudadanía. Sin embargo, su repetición cíclica - como advertía un editorialista del Diario del Hogar - promovió el establecimiento de un culto cívico que permitía al "pueblo" tener un lugar y un tiempo donde hacer sus ofrendas "ante el altar augusto de la madre Patria", ${ }^{28}$ al mismo tiempo que alimentó la creación de una memoria histórica en la que Cuauhtémoc ya tendría un lugar asegurado. La celebración ininterrumpida de esta efeméride a lo largo de los casi 25 años en la que se llevó a cabo dio cabida, por tanto, a la creación de un espacio de reflexión en torno al personaje, su papel histórico y su función simbólica, que encontró en la prensa de aquellos años - que era uno de los espacios por excelencia de la opinión pública - un lugar adecuado para su expresión. ${ }^{29}$ En las siguientes páginas nos ocuparemos de algunos de los temas que de manera recurrente se activaron cada 21 de agosto.

${ }^{27}$ Véase, por ejemplo, la celebración del 2 de abril de 1910 en Campos Pérez, "La república"; sobre este tema también Esposito, Funerals; sobre la conformación del calendario cívico en el siglo XIX, ZÁraTE Toscano, "La conformación".

${ }^{28}$ Diario del Hogar (21 ago. 1901).

29 Piccato, The Tyrany, sobre todo pp. 63-99. 


\section{CUAUHTÉMOC, HÉROE CLÁSICO Y ROMÁNTICO}

En el México del último tercio del siglo xIx $-\mathrm{y}$ muy acorde con la idea de crear relatos nacionales integradores - la línea que separaba la literatura de la investigación histórica era a veces tan delgada y esquiva que no traspasarla podía resultar difícil, y más cuando se trataba de un personaje como Cuauhtémoc, sobre cuya vida y muerte había tan pocos datos positivos, como muchos eran los relatos legendarios. ${ }^{30}$ Según la narración del prehispanista canónico de la época, Alfredo Chavero, en el tomo primero de México a través de los siglos, Cuauhtémoc, que había asumido responsabilidades políticas y militares desde muy temprana edad en el pueblo de Tlatelolco, fue declarado tlatoani a la muerte de Cuitláhuac, cuando era apenas "un mancebo". Sin embargo, esa juventud no fue óbice para que su alma abrigara "la más grande de las esperanzas”, que en el relato de Chavero habría de ser la de "hundirse con su pueblo sin miedo en el corazón ni vergüenza en el rostro”. Por eso, desde el primer momento, "México y su rey - deducía este autor[habían sido] dignos uno del otro". Y ese hundimiento que auguraba el historiador tuvo lugar no mucho tiempo después de su nombramiento como tlatoani, cuando, tras la caída de Tenochtitlán, después de dos meses y medio de asedio, él y "su pueblo" rendían sus armas y quedaban en manos de Cortés y sus ejércitos. Aunque según la versión de Chavero $-\mathrm{y}$ la de otros historiadores posteriores -, una vez derrotado, Cuauhtémoc intentó huir junto a su mujer y otros

30 VÁzquez, "La historiografía”; Ortiz Monasterio, México eternamente, pp. 44-51. 
miembros de la nobleza en una canoa, finalmente fue apresado por Alvarado y llevado ante la presencia de Cortés. En ese momento fue cuando, al parecer, dirigiéndose a Cortés, pronunció algunas de las frases que más celebridad han dado al personaje a lo largo de la historia y que Chavero reproducía en los siguientes términos: "Malintzin [léase Cortés], pues he hecho cuanto podía en defensa de mi ciudad y de mi pueblo, y vengo por fuerza y preso ante tu persona, toma luego este puñal y mátame con él". ${ }^{31}$ Sin embargo, la muerte no le llegó al joven rey tan rápido como al parecer él habría deseado, sino que antes fue sometido a la famosa tortura del quemado de los pies para que confesase dónde había escondido los tesoros del reino. Durante los siguientes tres años, en calidad de prisionero, fue trasladado de una ciudad a otra, hasta que finalmente fue ejecutado en torno al año 1524.

La vida de Cuauhtémoc había estado llena, por tanto, de un buen número de aquellas características que resultaban tan del agrado de la literatura romántica de la época y que además servían para poner de manifiesto todo un conjunto de valores éticos cuyo eje fundamental era, como señala Pablo Piccato, el honor, entendido como una virtud no sólo perteneciente al ámbito de lo privado, sino también de lo público, basada en la lealtad a las convicciones propias, en la honestidad y en la transparencia. ${ }^{32}$ Así pues, Cuauhtémoc había sido decidido y valiente, había tenido que hacer frente a un enemigo mucho

31 Chavero, Historia antigua, las citas en pp. 888-889 y 911.

32 Sobre el romanticismo en México, Illades, Nación, sociedad y utopia; el elemento del sacrificio fue muy habitual en la literatura mexicana de la época para exaltar valores nacionalistas; véase, por ejemplo, el estudio realizado por Petersen, “¿Sacrificar al héroe?”; la cuestión del honor en Piccato, The Tyrany, sobre todo p. 65 y ss. y pp. 172-173. 
más poderoso que él, pero, sobre todo, había llevado a cabo un acto de sacrificio sin igual, que demostró su honorabilidad y lo dignificó tanto ante su pueblo como ante la historia. Los artículos memorialistas que comenzaron a publicarse en la prensa cada 21 de agosto no dejaron de subrayar estas características, y aunque este tono fue más habitual durante el siglo XIX, se mantuvo con escasas variaciones hasta el final del porfiriato, pues todavía en 1909 se publicaron reseñas históricas en las que se alababa la actitud sacrificial de Cuauhtémoc, quien, a pesar de los horrores a los que él y los suyos fueron sometidos durante los días del asedio, prefirió persistir "obstinadamente en morir en aquel sitio con las armas en la mano" antes que traicionar sus convicciones internas. ${ }^{33}$

Para subrayar estos rasgos románticos que habían definido la ética del héroe azteca, uno de los recursos que se empleó con mayor frecuencia fue la presentación de una visión hiperbólicamente negativa de sus adversarios. Esto permitía hacer énfasis en dos cuestiones íntimamente relacionadas entre sí: por una parte, que aquella derrota había sido "mil veces gloriosa [pues] todo se [perdió] menos el honor" ${ }^{\prime 4}$ (tanto personal como nacional), y por otra, que su protagonista, Cuauhtémoc, debía presentarse ante la historia como una figura gigantesca, frente a un Cortés que no alcanzaba la talla de "un pigmeo". ${ }^{35}$ El conquistador extremeño y sus seguidores, por tanto, aparecieron descritos de forma habitual como individuos abyectos, traidores, salvajes y ruines, es decir, como nada mejor que "una horda de

33 Diario del Hogar (21 ago. 1909).

${ }^{34}$ El Monitor Republicano (21 ago. 1887).

35 El Siglo Diez y Nueve (22 ago. 1889). 
salteadores", ${ }^{36}$ que habían actuado cegados únicamente por la codicia material y sin el más mínimo escrúpulo moral. Y si ese impulso había sido el que había guiado sus acciones durante la guerra - salando el agua de los canales, por ejemplo, para impedir su ingestión, lo que provocó la muerte de mujeres y niños-, estuvo también presente una vez lograda la victoria, pues su perversidad se presentaba como algo inherente a su naturaleza y no como fruto del contexto bélico; de este modo, la derrota militar de Cuauhtémoc se veía compensada por la victoria moral del pueblo azteca.

Para ilustrar esta perversidad castellana, uno de los episodios a los que se aludió de forma recurrente fue aquel que hacía referencia al banquete que Cortés y los suyos organizaron en Coyoacán para festejar la toma de Tenochtitlán, pues este contexto posbélico permitía mostrar de forma más descarnada la barbarie castellana. Para la narración de este episodio, los articulistas de esos años utilizaron de forma habitual las crónicas de la época, sobre todo la de Bernal Díaz del Castillo, dando con ello mayor verosimilitud a sus narraciones. Así, por ejemplo, uno de los editorialistas de El Hijo del Abuizote, tras describir cómo la imperial Tenochtitlán había quedado reducida a escombros debido a la superioridad técnica castellana, pasaba a contar la celebración pantagruélica que tuvo lugar horas más tarde y que - según el relato de Díaz del Castillo - había sido "una orgía en la que el desorden no conoció límites”, en la que el vino corrió a torrentes y en la que incluso "tomaron parte las pocas mujeres castellanas que había entonces". ${ }^{37}$

36 Diario del Hogar (21 ago. 1898).

37 El Hijo del Abuizote (24 ago. 1898). 
Ante semejante disipación moral, la imagen del último emperador azteca se dibujaba en el horizonte como la de un ser virtuoso, sereno y magnánimo, procedente de ese Olimpo de perfección y grandeza que había formado "la maravillosa civilización azteca, jamás comprendida por los conquistadores". ${ }^{38}$ De este modo, igual que en la escultura erigida en el Paseo de la Reforma, en donde un Cuauhtémoc vestido con túnica a la romana y con un gesto solemne sostiene una lanza en la mano sin que nada denote su esfuerzo físico, ${ }^{39}$ en las notas de la prensa de aquellos años, así como en los discursos pronunciados a los pies de dicha estatua, menudearon las referencias clásicas para describir y calificar tanto al héroe como sus acciones. Tanto fue así, que ya para 1890, desde las páginas del Diario del Hogar, Gil Blas se quejaba del abuso de este tipo de comparaciones históricas y cuestionaba su pertinencia y su función pedagógica, pues “¿qué sabe el pueblo de Nelson o Amílcar? Lo que el pueblo necesita es que se le hable de lo nacional, de lo que tiene la obligación de venerar y admirar, ¿dónde está pues la utilidad de [este tipo de] discurso?". ${ }^{40}$

Sin embargo, para los escritores, académicos y publicistas de aquellos años, la tentación del recurso al universo clásico debió de ser tal, que muy pocos pudieron sustraerse a ella, sobre todo durante las postrimerías del novecientos. Así, un editorialista de El Siglo Diez y Nueve señalaba en 1896 que Cuauhtémoc debía haber nacido "en Atenas y haber tenido por cantor a Homero", porque "la fiereza de este

\footnotetext{
38 Diario del Hogar (21 ago. 1895).

39 Fulton, "Cuauhtémoc awakened".

40 Diario del Hogar (24 ago. 1890).
} 
rey americano, capaz de haber defendido como Leónidas el desfiladero de las Termópilas" así lo ameritaba; ${ }^{41}$ tres años más tarde, el Diario del Hogar publicaba un texto de Ignacio Manuel Altamirano, en el que el famoso literato afirmaba que Cuauhtémoc había sido incluso "más glorioso que el héroe homérico [Aquiles], porque como hijo de la realidad humana tenía el cuerpo todo vulnerable, sin embargo, no presentó en su carácter ni un ápice que pudiera ser herido por la burla o por el desprecio", algo de lo que -en opinión de Altamirano - no podía presumir el referido héroe griego y que hacía de Cuauhtémoc "el héroe completo". ${ }^{42}$

Frente a esta percepción tan solemne del emperador azteca, se hizo necesaria la supresión o en todo caso la reinterpretación de aquellos episodios menos gloriosos de su vida, como el de su intento de huida tras la caída de Tenochtitlán, que en las pocas veces que fue sacado a colación fue adecuadamente modificado. Dicha modificación se justificaba - para los que la esgrimieron como argumento - en la percepción de que buena parte de la historiografía mexicana que se había escrito hasta entonces había estado inspirada en planteamientos hispanófilos y que, por tanto, estaba claramente sesgada hacia esa parte de la herencia cultural mexicana y desdeñaba o minusvaloraba la importancia del legado azteca, como en este caso, en el que los hechos históricos habían sido tergiversados para manchar el honor del emperador azteca. Así pues, las veces que se aludió a este episodio se dijo que Cuauhtémoc había sido sorprendido en el momento en que intentaba salvar, metiéndolos en

${ }^{41}$ El Siglo Diez y Nueve (21 ago.1896).

42 Diario del Hogar (21 ago. 1899). 
una canoa, a su esposa y a su hijo, para evitar que acabaran convertidos en botín de guerra de los castellanos, pero en ningún caso dándose él a la fuga, pues bien sabía el último emperador azteca que su deber era "no abandonar este suelo mientras tenga un palmo libre donde sustentar la planta”. ${ }^{43}$

En tanto que héroe clásico y romántico, Cuauhtémoc inspiró asimismo multitud de narraciones, poemas, piezas musicales y obras de teatro, que, además de publicarse de modo independiente, fueron insertados de forma completa o fragmentaria en las páginas de la prensa con motivo de la efeméride, sobre todo durante los primeros años de la puesta en escena de la conmemoración. El mismo año de la inauguración del monumento, El Siglo Diez y Nueve incluía en su edición del 21 de agosto algunos de los poemas que iban a ser recitados en la ceremonia de ese día, entre ellos, una extensa oda del poeta poblano Eduardo del Valle, cuyos primeros versos rezaban así: "Brote la luz de inspiración ferviente/ y su claro fulgor conmigo sea/ para cantar con Cuauhtémoc valiente/ la gloria que como astro centellea// Recuerde yo las ínclitas acciones/ del azteca monarca denodado/ que hizo morder la tierra a las legiones/ del invasor audaz y afortunado". 44

En términos de creación literaria y de narración histórica, Cuauhtémoc resultaba, por tanto, un personaje de gran plasticidad y con muchas posibilidades para satisfacer los gustos estéticos de la época, al mismo tiempo que también permitía definir parte de las esencias patrias mexicanas en clave azteca - como, por lo demás, se estaba haciendo

43 Diario del Hogar (21 ago. 1907).

44 El Siglo Diez y Nueve (22 ago. 1887). 
también en el plano internacional $-{ }^{45}$ con la posibilidad de añadirle, al gusto, mayores o menores dosis de antihispanismo. Pero la figura de Cuauhtémoc sirvió, asimismo, para poner de manifiesto la importancia del honor en la actividad pública, pues su vida y su muerte - marcada en estos relatos por la lealtad a un conjunto de convicciones y valores y coherente entre los dichos y los hechos-debía resultar ejemplar para la ciudadanía, que podría encontrar en ella un conjunto de virtudes dignas de imitación, como consideraba buena parte de los hombres dedicados a la vida pública durante aquellos años. ${ }^{46}$

\section{CUAUHTÉMOC, UN EMPERADOR PRECURSOR \\ DE IDEAS LIBERALES Y REPUBLICANAS}

Estrechamente relacionado con esta visión romántica del héroe azteca se encuentra otro de los temas que se activaban con motivo de su conmemoración: el del tipo de gobierno bajo el que se regía el país y las ideas que lo inspiraban; dos aspectos que formaban, junto con su pasado, una parte importante de la definición de México como nación. Tras la restauración de la república en 1867, después del breve imperio de Maximiliano, una ola de fervor republicano había inundado la vida política del país. A partir de entonces, los dirigentes de los sucesivos gobiernos se esforzaron en demostrar que la república era el único régimen de gobierno en el que la nación mexicana podía llegar a realizarse plenamente y que cualquier otro pervertía su

${ }^{45}$ Tenorio, Artilugio, pp. 122-218.
${ }^{46}$ Piccato, The Tyrany, pp. 63-95 y 172-173. 
naturaleza más esencial. La república, entendida como sinónimo de independencia y como ausencia de monarquía, se convirtió en la utopía alcanzada que ahora había que conservar. ${ }^{47}$ Junto con esto, la doctrina liberal - en oposición al conservadurismo católico - se presentó como el corpus de ideas capaz de sostener a la república (que en ese momento era lo mismo que decir a la nación) y protegerla de posibles amenazas, tanto políticas como militares, procedentes tanto del interior como del exterior del país. ${ }^{48} \mathrm{La}$ Constitución de 1857 y las posteriores Leyes de Reforma serían el mejor ariete con el que combatir a los enemigos de la nación. Y para demostrar que esas ideas no eran fruto de una moda pasajera o que habían sido tomadas de tradiciones extranjeras, qué mejor que mostrar que ya estaban presentes desde la época de Cuauhtémoc.

En este sentido, fue habitual que el último emperador azteca fuera presentado en sus sucesivas efemérides como el promotor de la lucha por la independencia, la persona que por primera vez "enseñó a los hijos de México lo que vale la heroicidad en el cumplimiento del deber y les preparó el camino para su futura emancipación”, 49 que sería continuada tres siglos más tarde gracias al "arrojo de un humilde párroco [que] reconstruyó la nacionalidad perdida y revindicó a la raza muerta". ${ }^{50}$ Pero las acciones de Cuauhtémoc no habían inspirado únicamente al cura Miguel Hidalgo y a los insurgentes de 1810, sino que habían atravesado las décadas centrales del siglo xIx y habían servido de fundamento a

\footnotetext{
${ }^{47}$ Aguilar, "Dos conceptos".

${ }^{48}$ Hale, La transformación.

49 El Monitor Republicano (21 ago. 1887).

50 Diario del Hogar (21 ago. 1898).
} 
la gran obra legislativa sobre la que se sustentaba el México presente. Así lo expuso, entre otros, Aurelio Garay, en una extensa oda escrita con motivo de la primera conmemoración, en la que se incluía la siguiente estrofa: “ $i E s$ tu fe la que anima/ a Hidalgo y Juárez y tu fe su norma!/ ¡Tu fe quien los sublima/ y en libres los transforma!/ ¡Tu fe es la Independencia y la Reforma!". ${ }^{11} Y$ esta capacidad inspiradora de Cuauhtémoc sólo podía venir de dos pasiones muy republicanas: el amor a la libertad y el amor a la patria, esta última entendida, en opinión de uno de los redactores de El Hijo del Abuizote, como "el amor a la familia, el cariño al terruño, el cumplimiento de la ley, la pasión por el engrandecimiento nacional $[\mathrm{y}]$ el deseo de la mayor solidaridad", que eran los rasgos que habían caracterizado la personalidad de Cuauhtémoc. ${ }^{52}$ Ambas pasiones, patria y libertad, habrían sido las que le habrían impulsado a luchar contra el invasor extranjero - representado en la figura de los conquistadores - para defender "los derechos de su pueblo a ser libre [y] a seguir disfrutando de su nacionalidad" aun a costa de su propia vida. ${ }^{53}$

Si los argumentos en favor de presentar al último emperador azteca como el precursor de la independencia, aunque forzados, no resultaban contradictorios, no ocurría lo mismo con la función política que éste había ejercido como jefe máximo de un gobierno imperial, que, en su naturaleza, se parecía demasiado a aquel contra el que habían combatido apenas dos décadas atrás los republicanos que ahora

\footnotetext{
51 Diario del Hogar (21 ago. 1887).

${ }^{52}$ El Hijo del Abuizote (24 ago. 1898).

${ }^{53}$ El Siglo Diez y Nueve (22 ago. 1896).
} 
gobernaban. Sin embargo, esta contradicción fue aclarada por la prensa republicana desde el primer año de su ejecución, probablemente para evitar las posibles acusaciones del conservadurismo católico. Así, por ejemplo, el cronista de El Siglo Diez y Nueve señalaba que, si hasta entonces “jamás se había honrado en la libre república de México la memoria de un emperador", en el caso de Cuauhtémoc era necesario hacer una excepción, ya que él pertenecía a la saga "de los grandes caudillos de la resistencia nacional” que habían contribuido a la lucha por la liberación de México. ${ }^{54}$ Por su parte, El Monitor Republicano se apresuró a señalar que el "México republicano tributa el más justo de los homenajes de admiración y reconocimiento al que llevó en sus manos el cetro imperial del Nuevo Continente, no en obsequio de sus instituciones, que son aborrecibles, sino del más acendrado sentimiento de patriotismo"; por eso - continuaba el redactor de este editorial-

[...] en Cuauhtémoc no se ve al último descendiente de los reyes aztecas [...], al que disponía como absoluto de la vida y fortunas de sus súbditos, [sino que] vemos en él al héroe de la patria, al que sigue defendiendo con una altivez y una fiereza propia de los antiguos atletas, los derechos que representaba la nación de cuyos destinos estaba encargado. ${ }^{55}$

Pero si respecto a la visión de Cuauhtémoc como precursor de ideas liberales no había dudas dentro de la prensa que apoyaba este régimen de gobierno, a medida que Porfirio Díaz se fue perpetuando en el poder, y a medida que comenzó

${ }^{54}$ El Siglo Diez y Nueve (22 ago. 1887).

${ }^{55}$ El Monitor Republicano (21 ago. 1887). 
a consolidarse una oposición liberal reformista cuya crítica a la política porfiriana se fue haciendo cada vez más dura y sistemática, comenzaron a surgir ideas discrepantes respecto a qué era y cómo debía organizarse una república, unas ideas que acabaron incidiendo también en las lecturas que se hicieron del último emperador azteca en las sucesivas conmemoraciones. ${ }^{56}$ De este modo, para aquellos que consideraban que el buen funcionamiento de la república requería de una figura fuerte, capaz de dirigir con autoridad y maestría los destinos de la nación y cuya ausencia podía provocar consecuencias catastróficas, el último rey azteca debía encarnar esas características, que no por casualidad se parecían a las que se le atribuían al entonces presidente del gobierno; así lo hizo, entre otros, un editorialista de El Siglo Diez y Nueve, al señalar que, a pesar del carácter indómito de la raza azteca, "al faltarle [a ésta] el caudillo que la guiara en la tenaz resistencia de Tenochtitlán, fue reducida a la más denigrante esclavitud", ${ }^{57}$ como eventualmente podía llegar a sucederle a la nación mexicana en ausencia de don Porfirio. Por su parte, para quienes consideraban que uno de los fundamentos de la república era la alternancia en el poder, pues esto garantizaba la ausencia de corrupción y sancionaba el necesario apego a la ley, las semejanzas que encontraban cada vez con mayor frecuencia entre Porfirio Díaz y Cuauhtémoc les resultaban sospechosas, pues éstas no procedían, en su opinión, precisamente, de un mismo espíritu liberal que hubiera animado a ambos personajes, sino de la voluntad de don Porfirio de convertirse en el nuevo rey de México; como se advertía,

56 Knigth, "El liberalismo mexicano".

${ }^{57}$ El Siglo Diez y Nueve (22 ago. 1896). 
por ejemplo, en uno de los dibujos de El Hijo del Abuizote de 1889 (véase la figura 3), en donde quien aparecía sentado en el trono regio no era el último emperador azteca, sino el entonces presidente del gobierno.

Figura 3

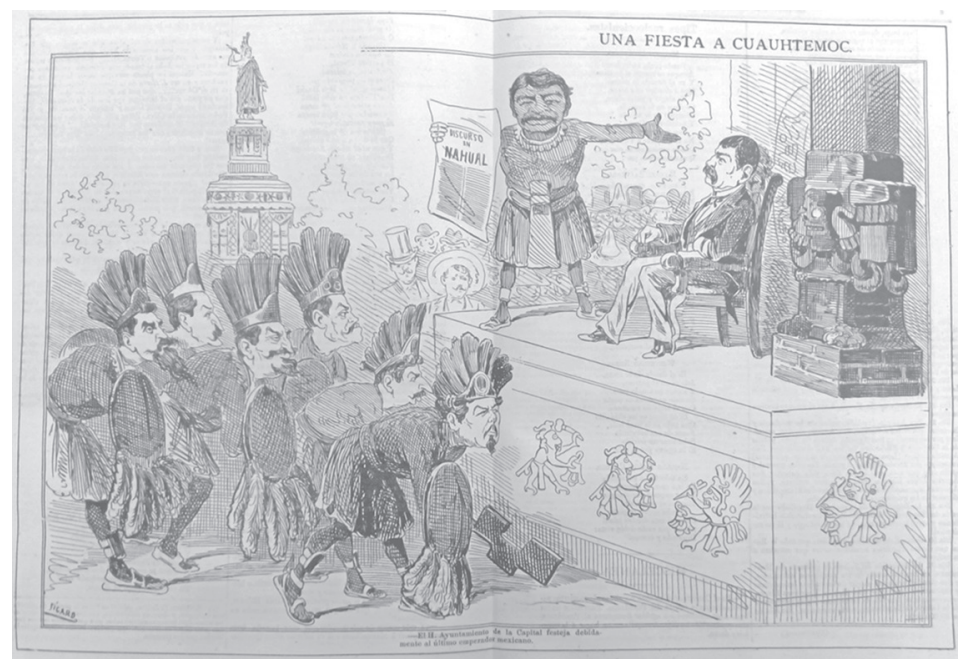

El Hijo del Abuizote (23 ago. 1889)

CUAUHTÉMOC Y LAS TRAMPAS DE LA RAZA

El tercer gran tema que se activaba en torno a la conmemoración del 21 de agosto era el de la raza, un tema por demás polémico en la historia de México y que, en los años en los que se ejecutó esta celebración, al hilo de la influencia de las ideas positivistas en el país, estaba dando lugar a la producción de toda una literatura más o menos científica que buscaba dar respuesta a lo que por entonces se llamó 
"el problema indígena". ${ }^{8}$ Para los intelectuales y hombres de letras de este fin de siécle, la multietnicidad existente en México desde los tiempos coloniales nunca resultó un elemento positivo para la consecución de la cohesión nacional; entre otras cosas - aunque esto ellos no lo solían señalar - porque detrás de las diferencias étnicas había una clara estratificación en términos socioeconómicos que alimentaba la idea de que cada raza, debido a una suerte de cualidades congénitas que no siempre se especificaban, estaba destinada a ocupar un lugar específico dentro de la sociedad, del que resultaba muy difícil, si no es que imposible, poder salir. ${ }^{59} \mathrm{En}$ el caso de la raza indígena mexicana, su lugar y función dentro de la sociedad porfiriana resultaba, además de polémica, ambigua; pues si, por una parte, era ensalzada en la medida en que representaban la parte más esencial y pura de la mexicanidad; por otra, era vista como un freno hacia el progreso y la modernidad que, precisamente durante los años en que se llevó a cabo esta conmemoración, comenzaba a dar sus mejores frutos en el país. Tradición y modernidad, esencialismo herderiano y darwinismo social confluían en la visión que se tenía del indígena presente; todo un cúmulo de contradicciones que el catolicismo militante de la época resolvía considerando que la cuestión de la raza era algo cultural y no biológico y que en realidad no había en torno al indígena más problema que el trato injusto del que era objeto. ${ }^{60}$

${ }^{58}$ Ejemplo de ello sería, entre otros, el libro de López Portillo y Rojas, La raza.

${ }^{59}$ Sobre la cuestión de la raza y de la raza indígena en México durante el porfiriato, Powell, "Mexican Intellectuals"; Rozart, Los orígenes; Tenorio, Artilugio, pp. 122-218.

${ }^{60}$ Para la posición de los católicos respecto a la cuestión de la raza, véanse 
Pero estas disquisiciones en torno al indígena contemporáneo afectaban en mucha menor medida al indígena histórico, que pertenecía a ese Olimpo de perfección y grandeza al que nos referíamos más arriba, capaz de construir una civilización tan compleja y tan perfecta como la que durante esos años se exponía por medio del pabellón de México en la Exposición Universal de París. A ese universo mítico pertenecía Cuauhtémoc, y todas las alusiones que en las sucesivas efemérides se hicieron a él, en tanto que representante de su raza, estuvieron encaminadas a reforzar esta percepción, subrayando en el último rey azteca cualidades como el valor, la entereza y la sabiduría. Sin embargo, como señalaron los cronistas y comentaristas de la conmemoración - sobre todo durante los primeros años -, la fiesta del 21 de agosto era "la fiesta del pueblo indio", ${ }^{61}$ era la fiesta de la raza en la medida en que se consideró que la sangre de aquellos aztecas míticos era la misma que aún corría "por las venas del pueblo mexicano". ${ }^{2}$ Pero, si esto era así, si el indígena contemporáneo compartía con Cuauhtémoc esos valores edificantes de la raza azteca, entonces por qué los intelectuales de aquellos años se empeñaban en hablar de lo indígena como un problema y no como una solución, por qué se buscaba sublimarlo en lugar de exaltarlo, por qué se había convertido en objeto de escarnio público y no en modelo.

Algunos dijeron que la raza había degenerado y esgrimieron argumentos de lo más variopinto para demostrar cuándo, cómo y por qué; al mismo tiempo que proponían

algunos editoriales de El País (28 ago. 1900; 7 sep. 1900; 12 sep. 1902); sobre este tema también PÉREz VEJO, “Extranjeros interiores”, p. 92.

61 El Siglo Diez y Nueve (22 ago. 1887).

62 Diario del Hogar (22 ago. 1907). 
fórmulas para su regeneración - como la educativa de Justo Sierra - que permitieran su redención y su utilidad dentro de la sociedad moderna. ${ }^{63} \mathrm{El}$ momento conmemorativo favoreció, asimismo, la formulación de propuestas de esta naturaleza y no faltó quien considerase que "el recuerdo del héroe azteca" podría servir para "despertar de su letargo secular a nuestra raza indígena". ${ }^{64} \mathrm{La}$ fusión de diferentes tiempos que implica toda conmemoración llevó en este caso a la creación de una línea de continuidad entre pasado y presente construida sobre un criterio tan altamente polémico como lo era la raza; el resultado fue, como veremos a continuación, menos provechoso para el indígena contemporáneo que para el liberal de aquellos años lo había sido la identificación del rey azteca con las ideas que señalábamos en el epígrafe anterior.

Como advertíamos en las primeras páginas de este trabajo, desde su primera ejecución, los organizadores de esta celebración consideraron que en ella tomaran parte representantes de los pueblos indígenas del Distrito Federal, cuyas músicas y danzas debían evocar el ambiente existente en la antigua Tenochtitlán antes de la llegada de los conquistadores castellanos, en esa Arcadia idílica en la que el emperador Cuauhtémoc habría brillado con luz propia, como volvía a hacerlo a partir de entonces gracias a la escultura de bronce instalada en el Paseo de la Reforma. "El eco triste y plañidero de las músicas indias - señalaba el cronista de El Siglo Diez y Nueve - con sus tambores, sus flautas,

${ }^{63}$ Núñez Becerra, “La degeneración”; también Pérez Vejo, “Extranjeros interiores".

${ }^{64}$ El Siglo Diez y Nueve (22 ago. 1889). 
sus teponaxtles [así como] el canto de los descendientes del héroe cuya glorificación se celebraba” permitirían recrear esa atmósfera y transportar a los participantes al tiempo mítico evocado. ${ }^{65}$

Además de la ambientación sonora, los representantes de los pueblos indígenas se encargaban, asimismo, de la creación de buena parte de la decoración floral con la que se engalanaban tanto el monumento como las tribunas oficiales. Junto a esta participación de carácter más escenográfico, los indígenas también contribuyeron - aunque de forma reducida, en comparación con otros grupos - en la producción discursiva. El promotor de esta iniciativa fue el indígena texcocano Oniquito Teodoro Juárez, quien durante los primeros años de la conmemoración se subió a la tribuna y pronunció discursos en náhuatl en los que, como ocurrió en 1887, además de hacer una exaltación de los últimos reyes aztecas, llevó a cabo toda una apología de su lengua, instando "al ciudadano presidente" y a las demás autoridades presentes a la creación de colegios y bibliotecas, así como a la formación de profesores "pagados por la nación” para que en esta lengua nacional “todos digamos ¡Viva México! ¡Viva Porfirio Díaz!”. ${ }^{66}$

Esta participación de los pueblos indígenas en la celebración no resultó, sin embargo, muy del agrado de una parte significativa de los comentaristas políticos de la época, que no encontraban en absoluto necesaria su presencia en un acto en el que, en su opinión, se debían promover las ideas liberales y no los exotismos folclóricos. Así, en 1889,

${ }^{65}$ El Siglo Diez y Nueve (22 ago. 1887).

${ }^{66}$ El Siglo Diez y Nueve (22 ago. 1887). 
un editorialista del Diario del Hogar se quejaba de que "tan simpático recuerdo" - el de Cuauhtémoc- hubiera quedado deslucido, debido a la "grotesca danza de indígenas, en traje de carácter”, que había formado parte de la celebración, "pues - continuaba argumentando este comentarista - no es con carnavalescas pantomimas propias de los festejos amistosos al Presidente con lo que debe glorificarse al héroe ante el pueblo y encender en sus corazones el culto del patriotismo, sino con la recordación de sus excelsas virtudes como patriota" ${ }^{67}$ Un año más tarde, otro editorialista, éste de El Monitor Republicano, hacía un comentario en un tono semejante al lamentar que el final de la ceremonia oficial hubiera resultado grotesca, debido a que los representantes de los pueblos indígenas "decidieron vestirse de fantasmones, dizque imitando los trajes y las danzas de los antiguos aztecas". ${ }^{68}$

Si este fue el tipo de comentarios que suscitó su participación física en la ceremonia, algo similar ocurrió con su intervención discursiva, que para más de uno resultó, si no grotesca, como las danzas y los trajes, al menos sí innecesaria e inútil. Así, por ejemplo, mientras un editorialista de El Monitor Republicano criticaba la fonética del náhuatl, advirtiendo que el ruso a su lado "nos parece un canto melodioso", 69 otro articulista, éste de El Siglo Diez y Nue$v e$, comentaba irónicamente que emplear el náhuatl en ceremonias cívicas como esa producía en la ciudadanía el mismo resultado que entre los feligreses utilizar el latín en las

${ }_{67}$ Diario del Hogar (25 ago. 1889).
${ }_{68}$ El Monitor Republicano (24 ago. 1890).
${ }_{69}$ El Monitor Republicano (24 ago. 1890). 
celebraciones religiosas: "que nadie entienda" de lo que se habla. ${ }^{70}$ Sin embargo, cuando diez años más tarde Luis Tejada pronunció desde la tribuna de los oradores una alocución en honor a Cuauhtémoc en inglés el día de la efeméride dirigida a los "muchos extranjeros" que habían acudido a presenciar la celebración, nadie se quejó del uso de esta lengua, aunque también debieron ser pocos - además de los extranjeros - los que le entendieron. ${ }^{71}$

A medida que fue concluyendo el siglo xIx y la conmemoración, como señalábamos más arriba, fue perdiendo lustre, se fue reduciendo la presencia de los representantes de los pueblos indígenas del Distrito Federal, a los que el Ayuntamiento de la Ciudad de México dejó de enviarles invitación oficial a partir de 1900; ${ }^{72}$ sin embargo, el discurso en náhuatl, pronunciado generalmente por el presbítero Sandoval, se mantuvo hasta la última conmemoración. El lugar de los pueblos indígenas en la celebración fue ocupado, como también dijimos, por niños procedentes de asilos católicos, que acudían a las inmediaciones del monumento del Paseo de la Reforma disfrazados con trajes de aztecas; de este modo se podía recrear el momento histórico, esquivando la incómoda presencia de los indígenas contemporáneos. Ya hacia el final de la primera década del siglo xx también desaparecieron los disfraces y los niños subían vestidos con sus uniformes escolares a cantar el Himno Nacional; o vestidos de blanco, como en la conmemoración del año del Centenario. Esta iniciativa de hacer desaparecer las caracterizaciones fue

70 El Siglo Diez y Nueve (23 ago. 1890).

${ }^{71}$ El Imparcial (22 ago. 1900).

72 AHCM, Festividades, vol. 1059, exp. 42. 
aplaudida desde los sectores más fascinados por el progreso, que consideraban que "los trajes aztecas de sacerdotes, guerreros y cortesanos, que tanto habían gustado y llamado la atención en años anteriores [...] estaban fuera de tono en la actualidad", pues la modernidad empujaba al país por otros derroteros y ya era hora de que esas rémoras del pasado se "despidi[eran] de nosotros para siempre". ${ }^{73}$

Así pues, al concluir el porfiriato nada quedaba en la conmemoración a Cuauhtémoc que remitiera a los pueblos indígenas contemporáneos. Esta celebración, que teóricamente habría sido la que más habría podido contribuir a su dignificación social y a su valoración histórica, acabó convirtiéndose en la celebración de una entelequia, pues la única raza a la que se exaltó fue aquella que aparecía escrita en documentos y libros, mientras que el indígena vivo continuó resultando una presencia incómoda, no sólo en la vida cotidiana de los habitantes de la ciudad, sino también en celebraciones cívicas como ésta.

\section{EPÍLOGO}

Después del proceso revolucionario vivido en México a partir de 1910, la conmemoración en honor a Cuauhtémoc, como le ocurrió a otras celebraciones porfirianas, desapareció del calendario cívico anual del país, a pesar del potencial que esta efeméride tenía para el giro populista de imbricaciones indigenistas con el que se invistió el nuevo régimen. ${ }^{74}$

${ }_{73}$ El Imparcial (22 ago. 1908).

${ }^{74}$ Algunas implicaciones culturales de esto pueden verse en Pérez MoNFORT, Estampas. 
Eso no significó, ni mucho menos, que se echara al olvido la memoria de Cuauhtémoc o que su evocación dejara de resultar ejemplificadora para las nuevas aspiraciones que animaban ahora al país; sólo hizo falta implementar algunas modificaciones a su interpretación para que ésta siguiera siendo útil. En 1922, por ejemplo, en la Exposición Universal celebrada en Río de Janeiro, Cuauhtémoc se convirtió en el protagonista de la representación de México en Brasil; de hecho, hasta se inauguró en la capital carioca una escultura del último emperador azteca, que era réplica de la que desde 1887 lucía en el Paseo de la Reforma y en torno a la cual, el entonces secretario de Educación Pública, José Vasconcelos, expuso su teoría de la raza cósmica, a pesar de que ésta estaba fundamentada en una raza distinta a la del héroe indígena. ${ }^{75}$ Unos años más tarde, en 1929, el prolífico historiador y autor de varios manuales escolares de historia, Alfonso Teja Zabre, publicaba un libro monográfico sobre el personaje - mitad histórico, mitad literario - en el que, dando continuidad a la teoría vasconceliana y manteniendo el tono encomiástico decimonónico, convertía al último emperador azteca en "Rey del tiempo y Emperador de una raza". ${ }^{76} \mathrm{El}$ mito de Cuauhtémoc se mantuvo vivo durante las décadas centrales del siglo xx y lo mismo sirvió para dar nombre a avenidas, parques, delegaciones y colegios, que para inspirar investigaciones históricas, que todavía hacia mediados de la década de 1960 insistían en ver al último rey azteca como “el ejemplar más acabado de un hombre en lucha por la

75 Tenorio, Artilugio, pp. 267-293; otros ejemplos de las nuevas lecturas que se hicieron de Cuauhtémoc durante el periodo posrevolucionario en Fulton, "Cuauhtémoc regained".

76 Teja Zabre, Historia, p. 92. 
libertad". ${ }^{77} \mathrm{El}$ altar de la patria creado en las postrimerías del siglo xix en torno a la estatua y a la efeméride de Cuauhtémoc no volvería a ser usado después de la caída del gobierno de Porfirio Díaz; sin embargo, el lugar de memoria ${ }^{78}$ que surgió gracias a él se mantuvo vigente durante mucho tiempo, probablemente hasta nuestros días.

\section{SIGLAS Y REFERENCIAS}

AHCM Archivo Histórico de la Ciudad de México, fondo Ayuntamiento y gobierno del Distrito; sección Festividades.

Aguilar, José Antonio

“Dos conceptos de república”, en Aguilar y Rojas (coords.), 2000, pp. 57-85.

Aguilar, José Antonio y Rafael Rojas (coords.)

El republicanismo en Hispanoamérica. Ensayos de historia intelectual y política, México, Fondo de Cultura Económica, 2000.

Bastian, Jean-Pierre

Los disidentes. Sociedades protestantes y revolución en México, 1872-1911, México, El Colegio de México, 1989.

Beezley, William, Cheryl Martin y William French (eds.)

Rituals of Rule, Rituals of Resistance. Public Celebrations and Popular Culture in Mexico, Wilmington, Scholar Resources, 1994.

77 Muriel, “Divergencias”.

78 Usamos el término "lugar de memoria” en el sentido que le asignó Nora, Les Lieux. 
Campos Pérez, Lara

"La república personificada. La fiesta porfiriana del 2 de abril", en Estudios de Historia Moderna y Contemporánea de México, 51 (ene.-jun. 2016), pp. 53-71.

Chavero, Alfredo

Historia antigua y de la conquista, vol. 1, en Vicente Riva PALACio (coord.), México a través de los siglos, México, Ballescá, 1887.

Cosío Villegas, Daniel

El Porfiriato. Vida política interior, t. 2, vol. 2, en Daniel Cosío Villegas (dir.), Historia moderna de México, México, Hermes, 1973.

Dumas, Claude

"El discurso de oposición en la prensa clerical conservadora de México en la época de Porfirio Díaz (1876-1910)”, en Historia Mexicana, xxxix: 1 (153) (jul.-sep. 1989), pp. 243-256.

Esposito, Mathew

Funerals, Festivals and Political Culture in Porfirian Mexico, Albuquerque, University of New Mexico Press, 2010.

Ferreyra Beltrán, Pablo Alejandro

"Cuauhtémoc, hombre y mito en la historia de México", tesis de licenciatura en antropología, México, Escuela Nacional de Antropología e Historia, 1983.

Fulton, Christopher

"Cuauhtémoc awakened", en Estudios de Historia Moderna y Contemporánea de México, 35 (2008), pp. 5-47.

"Cuauhtémoc regained", en Estudios de Historia Moderna y Contemporánea de México, 36 (2008), pp. 5-43.

García Quintana, Josefina

Cuaubtémoc en el siglo XIX, México, Universidad Nacional Autónoma de México, 1977. 
Gentile, Emilio

"Fascism as Political Religion", en Journal of Contemporary History, 25: 2/3 (1990), pp. 229-251.

Gillis, John R. (ed.)

Commemorations. The Politics of National Identity, Princeton, Princeton University Press, 1994.

Gómez IzQuierdo, Jorge (coord.)

Los caminos del racismo en México, México, Plaza y Valdés, 2008.

Hale, Charles

La transformación del liberalismo en México a finales del siglo XIX, México, Fondo de Cultura Económica, 2000.

Hobsbawm, Eric

“La fabricación en serie de tradiciones. Europa, 1870-1914”, en Terence y Hobsbaw (eds.), 2002, pp. 273-318.

Illades, Carlos

Nación, sociedad y utopía. El romanticismo mexicano, México, Conaculta, 2005.

Las otras ideas. Estudios sobre el primer socialismo en México, México, Era, Universidad Autónoma Metropolitana, 2008.

KNigth, Alan

"El liberalismo mexicano, desde la Reforma hasta la Revolución”, en Historia Mexicana, xxxv: 1 (137) (jul.-sep. 1985), pp. 59-91.

López Portillo y Rojas, José

La raza indígena, México, Imprenta Mariano Viamonte $\mathrm{Zu}-$ leta, 1904.

Mosse, George L.

La nacionalización de las masas, Madrid, Marcial Pons, 2007. 
Muriel, Josefina

"Divergencias en la biografía de Cuauhtémoc", en Estudios de Historia Novobispana, 1, 1966, pp. 53-114.

Nora, Pierre

Les lieux de mémoire, París, Gallimard, 1984.

Núñez Becerra, Fernanda

"La degeneración de la raza a finales del siglo xIx. Un fantasma ‘científico' recorre el mundo”, en Gómez IzQUierdo (coord.), 2008, pp. 67-88.

Ortiz Monasterio, José

México eternamente. Vicente Riva Palacio ante la escritura de la historia, México, Fondo de Cultura Económica, 2004.

PAni, Erika y Alicia SAlmerón (coords.)

Conceptuar lo que se ve. François-Xavier Guerra, historiador. Homenaje, México, Instituto de Investigaciones Dr. José María Luis Mora, 2004.

Pérez Montfort, Ricardo

Estampas de nacionalismo popular mexicano: ensayos sobre cultura popular y nacionalismo, México, Centro de Investigaciones y Estudios Superiores en Antropología Social, 1994.

Pérez Vejo, Tomás

"La difícil herencia: hispanofilia e hispanofobia en el proceso de construcción nacional mexicano”, en Pérez Vejo y SuÁRez Cortina (eds.), 2010, pp. 219-230.

"Extranjeros interiores y exteriores: la raza en la construcción nacional mexicana”, en YANKELEVICH (coord.), 2015, pp. 89-124.

Pérez Vejo, Tomás y Manuel Suárez Cortina (eds.)

Los caminos de la ciudadanía: México y España en perspectiva comparada, Madrid, Biblioteca Nueva, Publicán, 2010. 
Petersen, Amanda

“Sacrificar al héroe para fundar la nación? Clemencia de Ignacio Manuel Altamirano", en Literatura Mexicana, 25: 1 (2014), pp. 5-24.

Piccato, Pablo

The Tyrany of Opinion. Honor in the Construction of the Mexican Public Sphere, Duke, Duke University Press, 2010.

Powell, T. G.

"Mexican Intellectuals and the Indian Question, 1876-1911", en The Hispanic America Historical Review, 48: 1 (1968), pp. 19-36.

Ramírez, Fausto

"Vertientes nacionalistas en el modernismo", en El nacionalismo y el arte mexicano, México, Universidad Nacional Autónoma de México, 1986, pp. 111-167.

Rozart, Guy

Los orígenes de la nación. Pasado indígena e historia nacional, México, Universidad Iberoamericana, 2001.

Teja Zabre, Alfonso

Historia y tragedia de Cuaubtémoc, México, Botas, 1929.

Tenembaum, Barbara A.

"Streetwise History. The Paseo de la Reforma and the Porfirian State, 1876-1910”, en Beezley, Martin y French (eds.), 1994, pp. 127-149.

Tenorio Trillo, Mauricio

Artilugio de la nación moderna, México, Fondo de Cultura Económica, 1998.

Terence, Ranger y Eric Hobsbaw m (eds.)

La invención de la tradición, Barcelona, Crítica, 2002. 
VÁzquez, Josefina Zoraida

"La historiografía romántica en México", en Historia Mexicana, x: 1 (37) (jul.-sep. 1960), pp. 1-13.

Yankelevich, Pablo (coord.)

Inmigración y racismo: contribuciones a la bistoria de los extranjeros en México, México, El Colegio de México, 2015.

Zárate Toscano, Verónica

"La conformación de un calendario festivo en México en el siglo xix”, en Pani y Salmerón (coords.), 2004, pp. 182-214. 
